\title{
COLLEGIALITY AND OCCUPATIONAL CHANGE IN THE PRIESTHOOD*
}

\author{
Richard W. Bell \\ Loyola University of Chicago \\ John P. Koval \\ University of Notre Dame
}

\section{Introduction}

Perhaps no other occupational group is undergoing as much change as the Roman Catholic clergy. Not only are a sizeable number of men leaving the clerical role (N.C. News Service, 1971)--a fact that can be viewed as the tip of the iceberg of social change--but many of those who remain are producing important internal change. Some secretly flaunt tradition and traditional authority by their covert actions and life style. Others have organized themselves into extra-legitimate groups that effectively constitute contravailing power structures at the local and national levels. The purpose of this paper is to explore some of the internal changes in the role definitions, values, beliefs, and occupational behavior of a national sample of Catholic clergy.

It is an ever-popular notion that celibacy and the celibate life constitutes the basis for much of the unrest of the Catholic clergy (which may say more about the interpretors of the data than the data itself). Yet, there are other substantive issues that have received relatively short shrift but which are of major importance to the occupational role of the priest and the organizational structure in which that role is activated. Two such interrelated factors are the major focus of this paper--professional colleagueship (and collegial authority) as it relates to authority in a traditional bureaucratic structure. Autonomy, colleague authority, and colleague systems of social control are major hallmarks of a profession (Greenwood, 1957; Moore, 1970: 3-22; Taylor, 1968: 123ff). While the priesthood unfailingly is identified as one of the most long-standing of professions, none of these attributes have been a conspicuous characteristic of that group. Popular lore has identified issues related to celibacy as the cutting edge of change in the personal life styles of the Catholic clergy. Let us examine whether issues about colleagueship and collegial authority can be considered the cutting edge for occupational and organizational change.

$$
\text { Collegiality }
$$

\section{Setting}

One inescapable conclusion drawn from the literature is that collegiality is found in its purest forms among professionals (Ha11, 1946; Friedson, 1970; Taylor, 1968). Yet professional and colleague, like love and marriage, are not univocal terms even though they go together frequently. An omnipresent aspect of the culture of professionalism is the existence and functioning of numerous informal colleague grouns. Though of great importance to professional functioning these colleague groups are only one aspect of the total conception of professionalism.

Collegiality is a relationship that takes place mainly within the work context. Colleagues work together. It differs from friendship. The latter is an affective relationship; the former is instrumental. Colleagues may be friends but they need not be. Collegiality also differs from fraternity which is a sort of diffuse affective relationship based on a "consciousness of kind."

In the recent past the so-called "clergy culture" has manifested several characteristics of what has often been referred to as a collegial environment (Kennedy, 1968). The traditional social system of the clergy, its "culture" and the characteristics of that culture lead us to conclude it was more fraternal than collegial when viewed 
in the most comprehensive sense of the meaning of collegiality. Two elements were missing.

First, the critical element of colleague authority system and an emphasis upon horizontal authority in colleague control systems did not exist. Second, the purpose and function of the "clergy culture" was not grounded in establishing and maintaining group goals based on expertise--this function was performed by the organizational functionaries in the bureaucratic structure. The goals were more characteristicallv social, recreational, and fraternal. Thus, the mutual support provided by the men was one of reaffirming personal commitments to the role and providing primary group relations in a rather caste-oriented church.

\section{Structure}

All the members of a given profession can loosely be called colleagues. Strictly speaking, however, collegial groups are small and limited in size. Membership is voluntary and unofficial. They are primary groups in intimate interaction in the work setting. Colleague groups tend to be temporary and to break up when their task is completed or when they no longer fulfill their functions of intellectual stimulation, etc. Colleague groups tend to have an informal rather than a formal structure. They are esoteric in that their concerns tend to be specific to the group. Colleague groups tend to arise where professionals function in spatial propinquity.

Relationships within the colleague groups tend toward the cooperative rather than the exploitative or competitive. Decision-making and goal setting tend to be democratic based on an egalitarian or peer relationship rather than a superordinate-subordinate configuration. Authority is horizontal and shared rather than formal, authoritarian and hierarchical.

\section{Functions}

Colleagues share knowledge, consult with one another, plan and set goals cooperatively Their central concern is the production and utilization of ideas in their concern for the advancement of the profession and the colleague group and the service of their public(s).

Colleague groups function informally in the control of entry into their group, in the division of labor, in defining the level of participation of their members, in the recruitment of new members (through sponsorship) and in the control of their total work situation. Colleagues also exercise informal controls over each other by setting ethical norms and standards of performance and by evaluating the activities of the members. Colleague groups are characterized by peer accountability and shared responsibility. Finally, colleagues are expected to support one another in their work and to exhibit loyalty toward one another.

The horizontal authority structure so characteristic of collegial groups will serve as an entry point in our examination of collegiality among priests. Other entry points are possible. The authority structure was chosen as particularly germane to the present state of the Catholic clergy and as the most sensitive predictor of the presence of collegial attitudes available from the data at hand.

\section{The Research}

Data for this paper are drawn from a national study of the Catholic clergy completed by the authors in December, 1970. The research was supported by a grant from the National Federation of Priests' Councils and was designed as a study of its national membership. A census of the NFPC membership was first conducted and resulted in an enumeration of 23,727 men. These census figures represent cooperating affiliate organizations from 93 of the 150 local dioceses in the country and 26 of the 27 regional 
provinces into which they are subdivided. The population was then stratified by diocese and province and a one in eight probability sample of 2962 priests was drawn from the census population. One hundred and thirty-two men were deleted from the original sample since they turned out to be either deceased, retired, or resigned--the study population was defined as active clergy only. The final useable returns reported in our study constitute 1774 Catholic clergy which represents a 63 per cent response rate.

\section{A Typology of Collegiality}

Collegiality in the Catholic Church appears to be differentially interpreted in at least three major ways. The church hierarchy, for the most part, tends to interpret collegiality as an important ingredient in renewing a traditional hierarchical structure. There is an emphasis upon shared authority but it tends to be limited to a broadening of the base of authority to the bishops of the world. The clergy role in this organizational definition of collegiality is advisory, however, rather than deliberative. This process has collegiality emanating from the hierarchical structure of the organization and controlled by it.

Priests with this orientation are characterized by a commitment to the formal, hierarchical structure of the church. Their service is to the organization and to its authorities. They feel that the setting of goals, the making of decisions and the determination of the dimensions of priestly existence are up to church authorities. They stress the priestly and hierarchical aspects of the ministry.

The second major theme in defining collegiality in the priesthood emanates mainly from priests themselves and is of a rather different character. Here, the central emphasis of collegiality is upon shared decision-making and authority of all ordained clergy. The bureaucratic organizational structure of the church is viewed as an adminstrative structure that is intended to carry out and implement decisions resulting from the collegial decisions of all priests.

This second orientation has the organization as a vehicle for professional activities. It stresses values such as participation in decision-making and goal setting, horizontal authority structures, autonomy, peer accountability, etc. The ideal is team ministry confined to priest-professionals.

A third orientation favors the widest possible shared participation in the ministry and the determination of church policy. Laymen as well as the hierarchy and priestprofessionals should share in these functions. This orientation both dilutes professionalism and radically deemphasizes the bureaucratic and formal organizational aspects of church structure. The emphasis of this group is the needs of people rather than those of the organization or the autonomy of professional behavior. Their idea is a shared ministry with a blurring of the boundaries between episcopal authorities, priest professionals and laymen.

These three interpretations can be applied in two general ways: (1) how they relate to the personal-occupational behavior of the priest; and (2) how they relate to the organizational bureaucrats--the hierarchy, the religious-occupational practitioner-the clergy, and the clients of the religious organization--lay people. The second and broadest network of implications has been selected for this analysis.

The Constructed Typology of Collegiality

As indicated above, the distinguishing characteristic of collegiality upon which we intend to focus is the extent of shared decision-making supported by the American Catholic clergy as such decisions involve either the hierarchy (the Pope, Cardinals, or Bishops), the ordained clergy and non-clerical laymen. Four items from a 12-item 
"Decision-making battery" in the Celibacy Study were selected as appropriate for our purposes. They dealt with participation in decisions concerning: (1) selection of a local bishop, (2) appointment of pastors in local diocese, (3) changes in religious ritual, (4) and the use of local diocesan funds. Individuals or groups that could be indicated by respondents as participants in making those decisions were one, or some combination of the following: the Pope, the College of Cardinals, International Council of Bishops, the National Council of Bishops, the local bishop, local pastors, individual priests, priests' senates or associations, local parish councils, diocesan parish councils, and national pastoral councils.

The criteria for our selection of the above cited items were three-fold. First, the items were intended to be restricted to decisions that bear upon local affairs. Second, such decisions traditionally were the prerogative of the hierarchy--the first five choices. Finally, they involved questions currently being critically reexamined by all parties concerned with an eye to either maintaining the traditional decisionmaking structure or expanding it to include clergy and/or laymen.

The patterns of responses to these items are considered an operational definition of their preferences for different levels of involvement within a decision-making context. For purposes of simplicity the possible combinations of decision-makers involved in each of the four items selected were reduced to three. First, cases in which one or more members of the hierarchy should be involved in the decision. Second, cases in which one or more types of clergy groups should be involved in the decision. Third, cases in which one or more types of lay groups should be involved in the decision. On each item a respondent could have one of eight patterns dealing with none, one or some combination of these groups. We choose to deal with the three specific patterns.

1. Hierarchically Centered Decisions. Those respondents who prefer decisions on the above four matters to involve only the hierarchy but not clergy or laymen.

2. Clergy Centered Decisions. Those respondents who prefer decisions to involve only the hierarchy and clergy but not laymen.

3. Egalitarian Decisions. Those respondents who prefer decisions to involve the hierarchy and the clergy and Catholic laymen.

Treatment of the data in this manner resulted in an empirical distribution of the 1774 men in the study into three groups. The "Hierarchicals" consist of 382 respondents or 21.5 per cent of the men in our study. "Clericals" consist of 175 men representing 9.9 per cent of the respondents. "Egalitarians" consist of 373 men and represent 21 per cent of the total men in the study. In all, $930 \mathrm{men}$, or 52.4 per cent of the sample fall into one of the three constructive types.

In spite of the rather stringent criteria for classifying the men into three types, slightly over half the men in the sample are, in fact, so classified. We consider this to be supportive of our hypothesis that three distinctive modes of orientation concerning collegiality do exist, which can be used to discuss clergy positions about decision-making in the church. The fact that nearly half of the men in the study do not fall into one of our three types poses a problem in our ability to generalize the findings but is not considered a serious impediment. First, what follows is an analytical rather than a generalizing, work. Second, we are speaking of common interest groups and the commitments each of the groups have to the collegiality theme. It is their effectiveness rather than size that leads to an answer to the question of persistence or change in the character of the Catholic church.

Some Selected Demographic and Personal Characteristics

The three types of clergy identified in this paper are distinguishable in a number of important ways. The Hierarchical Collegials--those most committed to a traditional, institutional and hierarchical definition of collegiality--are older, most characteristically pastors, and have a slight tendency to live in small city or rural areas. 
Table 1. Summary of Selected Background Characteristics of Collegial Types (reported in percentages)

Characteristic

Present Age

Under 35

Under 45

Present Position

Pastor

Assistant/Associate, other

Hierarchicals

$(\mathrm{N}=382)$
Clericals

$(\mathrm{N}=175)$
Equalitarians

$(\mathrm{N}=373)$

Present Residence

$\begin{array}{llll}\text { Rural-town-small city } & 50 & 43 & 38 \\ \text { Moderate sized } & & & 57 \\ \text { city/urban area } & 43 & 47 & 05 \\ \text { No answer } & 07 & 10 & \end{array}$

Socio-Political Views

Liberal/ultra-liberal

10

28

Position on Celibacy

Favor optional celibacy

Definitely/probably marry if law changes

46

77

07

12

27

In contrast, the Egalitarian Collegials--those committed to an expanded, nontradition, horizontal, and non-existing definition of collegiality--are relatively young, occupy positions of assistants or specials, and tend to reside in urban areas or moderate sized cities. The Clergy Collegials--those supporting an expanded but essentially clerically-based collegial orientation--stand in the middle of the two above groups. They are more solidly middle-aged, with a slight plurality of pastors and a healthy proportion in special assignments or assistants.

While there is relatively little difference in political affiliation of the three groups, approximately 90 per cent of the Hierarchical types describe their socio-political views as moderate or conservative. Egalitarian types, on the other hand, have 60 per cent of their numbers who consider themselves 1iberal or ultra-liberal in their socio-political views. The Clergy type is near evenly split between liberal and moderate-to-conservative orientations with a slight edge in the moderate-conservative direction.

When it comes to a major social issue of the day--celibacy--the differences between the three types show up in technicolor. Eighty per cent of the Hierarchical types do not favor optional celibacy. Eighty per cent of the Egalitarians do favor optional celibacy. The Clerical types are evenly divided between favoring and disfavoring such a change. Finally, approximately one in four Egalitarians would definitely or probably marry if the law did change and another one in four would consider marriage if the church laws concerning celibacy were to change. Neither Hierarchicals nor Clericals are inclined to pick up their option to marry if the laws did change. 
The Ideal Occupational Role

The history of human endeavors is strewn with examples of ideals never realized. Nevertheless, an examination of the emphasis placed upon ideal priests' activities can be indicative of the orientations of role incumbents.

In the recent past the role of the priest has been relatively static (Fichter, 1966). Dimensions of the role had been standardized. Few ventured beyond the set boundaries established by law and venerable tradition. Since Vatican II options have expanded considerably; alternatives have been legitimized. It is the nature of an option that it can be actualized or not. The data indicate that our three analytical types favor different options and have different priorities. In other words, they have differing views of the appropriate components of the occupational role.

Hierarchicals

Hierarchicals emphasize the "priesthood" and the organization of the church in their definition of the ideal. Great improvement is needed in being men of prayer, extending the priesthood by recruiting vocations and upgrading their field of knowledge by studying scripture and theology. Their next major concern is the local parish. They favor improvement in building a Christian community among parishioners, making the parish liturgy more meaningful, making converts and teaching religion in the grammar school. A relatively small proportion of Hierarchicals favor improvement in the performance of priests in racial justice, community organization, ecumenism, priests' senates and associations, the peace movement and experimental ministries. Such activities are peripheral to their definition of the ministry. What has been done should be continued and intensified. Hierarchicals look to tradition and the hierarchy to tell them what the role of the priest should ideally be. They are most at home in the traditional, local parish, where change is an intruder.

Clericals

Clericals are a mixed bag. They tend to agree with Hierarchicals in their emphasis on the priesthood and concentration of role performance in a parochial setting. Clericals too stress improvement in prayer life, study of scripture and theology, seeking vocations. Clericals are more amenable to change where it is concentrated in the parish setting. They place great value on updating the liturgy and building a Christian community--considerably more than do Hierarchicals. Clericals tend to eschew variations of the traditional parish functions and feel that there is little need for improvement--for example, in teaching in the grammar school or daily Mass. They see room for improvement mainly in transforming the parish and preparing themselves to do this. Clericals show low to moderate interest as a group in extra-parochial activities. Ideally they feel the need for a moderate improvement in working with senates and associations, racial justice and ecumenism. Clericals show low concern for upgrading priestly activities in peace movement or experimental ministries. They are most at home in the progressive parish where they can apply locally the new theology, Vatican decrees, develop community and hold relevant liturgies.

Egalitarians

The Egalitarian shares with the Clerical a strong orientation toward improving the parish and his own professional and spiritual effectiveness. Egalitarians have the highest discrepancy between the real and ideal. Their highest priority is the modernization of the parish. Like the Clericals, they place low priority on some traditional parochial activities they consider passé and irrelevant. 
Table 2. Ideal Activity of Priests Rated High and Discrepancy Between Ideal and Actual Activities

(reported in percentages)

\begin{tabular}{|c|c|c|c|c|c|c|}
\hline \multirow[t]{2}{*}{ Activity } & \multicolumn{2}{|c|}{$\begin{array}{l}\text { Hierarchicals } \\
\qquad(\mathrm{N}=382)\end{array}$} & \multicolumn{2}{|c|}{$\begin{array}{l}\text { Clericals } \\
(\mathrm{N}=175)\end{array}$} & \multicolumn{2}{|c|}{$\begin{array}{l}\text { Eg alitarians } \\
\qquad(\mathrm{N}=373)\end{array}$} \\
\hline & Ideal & Disc. & Ideal & Disc. & Ideal & Disc. \\
\hline Men of prayer & 88 & 77 & 88 & 8.4 & 90 & 86 \\
\hline $\begin{array}{l}\text { Working to make the liturgy more } \\
\text { meaningful to people }\end{array}$ & 75 & 49 & 87 & 72 & 93 & 87 \\
\hline $\begin{array}{l}\text { Keeping up with the latest develop- } \\
\text { ments in scripture and theology }\end{array}$ & 68 & 58 & 83 & 78 & 86 & 83 \\
\hline Instructing converts & 64 & 48 & 48 & 34 & 35 & 21 \\
\hline Fund raising & 09 & $31 *$ & 04 & $45 *$ & 02 & $51 *$ \\
\hline $\begin{array}{l}\text { Administration of parish buildings, } \\
\text { funds, and lay personnel }\end{array}$ & 17 & $42 *$ & 07 & $59 *$ & 03 & $71 *$ \\
\hline $\begin{array}{l}\text { Active involvement in ecumenical } \\
\text { ministries }\end{array}$ & 25 & 19 & 36 & 34 & 56 & 54 \\
\hline $\begin{array}{l}\text { Actively working with priests' associa- } \\
\text { tions or senates for reform or } \\
\text { renewal in my diocese }\end{array}$ & 33 & 22 & 50 & 38 & 67 & 59 \\
\hline Teaching religion in the grammar school & 54 & 41 & 37 & 25 & 23 & 12 \\
\hline Working with community organizations & 28 & 22 & 40 & 34 & 55 & 53 \\
\hline $\begin{array}{l}\text { Active involvement with groups work- } \\
\text { ing for racial justice }\end{array}$ & 29 & 24 & 39 & 37 & 61 & 59 \\
\hline $\begin{array}{l}\text { Active involvement in the Peace } \\
\text { Movement }\end{array}$ & 10 & 06 & 19 & 18 & 42 & 41 \\
\hline Offering daily Mass & 91 & 16 & 82 & 00 & 65 & $22 *$ \\
\hline Actively recruiting vocations & 66 & 59 & 56 & 53 & 41 & 40 \\
\hline High school teaching (other than religion) & 10 & 05 & 09 & 01 & 15 & $02 *$ \\
\hline $\begin{array}{l}\text { Actively searching for new areas of } \\
\text { ministry (experimental ministry) }\end{array}$ & 06 & 02 & 16 & 15 & 45 & 43 \\
\hline $\begin{array}{l}\text { Developing a sense of Christian community } \\
\text { among parishioners }\end{array}$ & 69 & 52 & 85 & 74 & 92 & 87 \\
\hline $\begin{array}{l}\text { Acquiring professional competence in } \\
\text { secular areas }\end{array}$ & 11 & 06 & 16 & 13 & 23 & 20 \\
\hline
\end{tabular}

*The asterisks indicated over-achievement or over-conformity of the ideal. 
Despite some similarities Egalitarians show marked differences from Clericals. They are most expansive about the role of the priest. They tend to be "occupational cosmopolitans" in their concerns. They place a very strong emphasis on the need to improve the performance of priests in a variety of extra-parochial areas, including racial justice, priests' senates and associations, ecumenism, community organizations, experimental ministries, etc. They have a stronger sense of the need to update the priestly role not just in the parish setting but outside of that context. They are most at home in a progressive parish where they can both experiment with improving the service or people and have the leisure for a wide range of extra-parochial activities. Their concern runs to the updating of the whole church structure, not just the parish. Tradition and authority are not their overriding guidelines, but rather adapting the church and their ministry to the needs of people.

Role Behavior: Social Issues

Significant differences between our three analytical groups occur when we examine their performance in certain activities in their priestly role. Respondents were requested to state whether they "had already done" five admittedly deviant or. liberal activities.

Table 3. Reported Participation in Selected Social Action:

"Have Done It" - "Have Decided To do It"

(reported in percentages)

\begin{tabular}{lccc}
\hline Activity & $\begin{array}{c}\text { Hierarchicals } \\
(\mathrm{N}=382)\end{array}$ & $\begin{array}{c}\text { Clericals } \\
(\mathrm{N}=175)\end{array}$ & $\begin{array}{c}\text { Egalitarians } \\
(\mathrm{N}=373)\end{array}$ \\
\hline $\begin{array}{l}\text { Counseling couples to } \\
\text { follow own conscience } \\
\text { about contraceptives }\end{array}$ & 20 & 44 & 80 \\
$\begin{array}{l}\text { Getting involved in civil } \\
\text { rights activities }\end{array}$ & 11 & 27 & 35 \\
$\begin{array}{l}\text { Going out socially with a } \\
\text { woman friend }\end{array}$ & 12 & 21 & 38 \\
$\begin{array}{l}\text { Public stand against Vietnam } \\
\begin{array}{l}\text { Speaking out against } \\
\text { celibacy law }\end{array}\end{array}$ & 07 & 15 & 36 \\
\hline
\end{tabular}

One in five Hierarchicals privately counsels couples to follow their own consciences in the use of contraceptives. About half of the Clericals and four-fifths of the Egalitarians have done this or have decided to do it. Such an activity flies in the face of institutional pronouncements.

Egalitarians are also more likely than the other groups to violate the traditional canons of the celibate clerical culture. Thirty-eight per cent of the Egalitarians report going out socially with a woman friend compared to twelve per cent of the Hierarchicals (Clericals - 21\%). Twenty-eight per cent of the Egalitarians have taken a public stand against the celibacy law. Two per cent of the Hierarchicals have done so. 
A greater proportion of Egalitarians than the other two types report activity in the civil rights movement and public opposition to the Vietnamese War. More than one-third of the Egalitarians report such activity. One-fourth of the Clericals and one-tenth of the Hierarchicals report involvement in civil rights activities. Fifteen per cent of the Clericals and a modest seven per cent of the Hierarchicals have taken a public stand against the Vietnam War. Egalitarians have a tendency to actively expand the limits of the role behavior of the priest to causes (peace and civil rights) theoretically endorsed but little acted upon by Church leadership.

\section{Role Stress and the Three Types}

Respondents were asked to reply to a list of eighteen areas of possible stress in the institutional, work and personal context of the priest's life. The reported data include both those who felt the stress was serious enough to make them consider resigning and those who felt the stress was serious but not enough to make them consider resigning.

Hierarchicals' Stress Profile

Hierarchicals exhibit a relatively low stress profile. They seem the most comfortable of the three types in the church as it exists today. Their orientation of collegiality is the one presently in ascendency. They find the clerical life style relatively unstressful. Only a small minority report loneliness and poor spiritual life as problems. Lack of support from fellow clergy troubles a few in their work setting. All in all, the institution, work and personal life are congenial.

Clerical Stress Profile

Clericals report moderate stress. The personal context contains the highest stress item, loneliness. Clericals find the celibate clerical culture less congenial than Hierarchicals. This can be seen by the incidence of personal stress in such areas as desire to marry, desire for more freedom for personal growth and need for sexual intimacy. One in four feels stress due to a lack of a good spiritual life.

One-fourth of the Clericals report stress from the institutional context. This stress is related to the exercise of authority in the church. Twenty-eight per cent report serious stress from a lack of leadership from those in authority. Disappointment with the church's stand on race and birth control and the slow pace of change after Vatican II are significant sources of stress.

Clericals in their work context also report serious stress. About one-fourth report frustration in their work is serious. Twenty-two per cent feel a lack of support from their fellow clergy. Clericals as a group have a sizeable minority of their membership heavily straining under present conditions.

Egalitarian Stress Profile

Egalitarians report extremely high stress levels. The authority structure of the church as presently operating, the clerical life style and problems in their day-today work all add up to a high incidence of reported stress for the majority of Egalitarians.

Egalitarians find the current situation of confining collegiality to the hierarchy most distressing. A majority of them report serious stress from disappointment with the church's stand on certain social and moral issues, a lack of leadership from those in authority, and the slow pace of change since Vatican II. 
Table 4. The Character and Extent of Reported Stress:

Institutional, Work and Personal Context

(reported in percentages)

Stress Item

Hierarchical

$(\mathrm{N}=382)$

Clericals

$(\mathrm{N}=175)$

Egalitarian

$(N=373)$

A. Institutional Context

Slow pace of change after Vatican II

08

21

50

Disappointment in church's stand on certain social or moral issues (e.g., race, birth control)

10

24

54

Conviction one could do more "outside

church structure"

03

06

15

Lack of leadership from those in authority

15

28

52

B. Work Context

Lack of support and encouragement from

fellow priests

Frustrated in efforts to work

Conflict with a particular pastor or bishop

Conflict with parishioners

04

05

05

C. Personal Context

Loneliness

Desire to marry

Didn't have vocation to priesthood

in first place

Desire for more freedom for personal growth

Desire for another career

Poor spiritual life

Reality shock after seminary

Personal insecurity

Need for sexual intimacy

08

17 
Fifteen per cent think that they could do more outside church structure. The greatest source of serious stress for Egalitarians is found in the institutional context.

The celibate clergy life style is the next greatest source of serious stress for Egalitarians. Loneliness, a desire to marry and a need for sexual intimacy are serious factors. Twenty-seven per cent desire more freedom for personal growth.

Egalitarians also suffer from serious stress in their work context. Normally this will be in a parish. There they report frustration in their work and a lack of support from fellow clergy as sources of serious stress. The fact that their stress is highest seems to indicate that the church structure of which they are a part is farthest from actualizing their conception of collegiality and personal autonomy.

Egalitarians are a sizeable group--at least as large as Hierarchicals--and twice as large as Clericals. The level of stress of the Egalitarians as a group is so high as to constitute a situation of serious proportions for manpower maintenance. Egalitarians are a younger group than the others. They are the most likely to settle their stress by removing themselves from its source.

\section{Church Structure and Authority}

A fourteen-item battery of questions was employed in the study to examine the extent and magnitude of structural change supported by various groups within the Catholic clergy. The items were selected as well-known options for potential change that have been informally discussed among the clergy both during and after Vatican II. None of the items, however, were part of church policy or structured into its institutional character at the time the instrument was completed. Almost all of the proposals were still part of the "possible future" for the church. At best, they appear as experimental programs in a few dioceses in the country.

A striking difference is evident when one examines all fourteen proposed changes in the light of the three types of priests. Egalitarians, for example, roundly support thirteen of the fourteen changes offered in the questionnaire. The only exception is the phasing out of the Catholic educational system. The homogeneity of Egalitarians in supporting these issues is reflected by the median support scores of 79 per cent for all fourteen items. Hierarchicals, however, had a majority of men supporting only four of the fourteen items. Their median support score of 31 per cent reflects $a$ less enthusiastic outlook towards change. The Clericals, again, are somewhat divided in features of change they would support. Two-thirds or better support half the change items while on the other half less than 50 per cent do so. This, too, is reflected in their median support score of 55 per cent.

The three factors supported by nearly all the Egalitarians are:

1. Pastor's appointment on ability and competence rather than seniority.

2. Pastoral councils of religious lay and priests working in conjunction with the bishop.

3. Redirecting a substantially greater portion of the church's income to meet the needs of the poor.

A majority of Hierarchicals also support those same items but to a lesser degree. In this case, three out of four typically support the first two items and approximately half would favor redirecting additional funds of the church in meeting the needs of the poor. It is only in these three items, incidentally, where there is anything that approximates a convergence of emphasis on the part of the men of the three groups.

The most significant difference between Hierarchically centered and Egalitarian centered clergy occurs at the level of the definition and activities of the Catholic clergy themselves and the range of autonomy they see desirable. Eight of ten 
Table 5. Favored Institutional Change in the Church and the Discrepancy Between Favored and Expected (reported in percentages)

Organizational Change Favored

$\begin{array}{ccc}\text { Hierarchicals } & \text { Clericals } & \text { Egalitarians } \\ (\mathrm{N}=382) & (\mathrm{N}=175) & (\mathrm{N}=373)\end{array}$

Favor Disc. Favor Disc. Favor Disc.
Pastors appointed principally because of ability and competence rather than seniority

Redirecting a substantially greater portion of Church's wealth to meeting the needs of the poor
76

53
21

13

71

Ongoing pastoral councils in every diocese
of elected priests, religious and lay people

working in conjunction with the bishop

01

44

03

24

12

93

27

97

15

A limited term of office for the position of pastor

A limited term of office for the position of ordinary

Priests should be encouraged and permitted to enter the professions (medicine, government, law, etc.) if they feel there is a ministry

they wish to pursue in that area

17

National transfer program to make feasible the movement of priests between dioceses

46

Parish priests should be allowed options for their personal lives (where to live, wear, etc.) 16 05*

$77 \quad 38$

Standards of professional performance set by priests for priests and enforced by priests

Sabbatical leaves for priests to use as they see fit

Phasing out of Catholic grammar school system Approval of small group ministries, floating parishes etc.

$57 \quad 25$

$39 \quad 14$

$1712 *$

$1807 *$

8605

$97 \quad 15$

Election of the Pope by the bishops of the world,with a limited term of office

\begin{tabular}{|c|c|c|c|c|c|}
\hline 20 & 11 & 47 & 33 & 80 & 53 \\
\hline 07 & $02 *$ & 30 & 07 & 59 & 19 \\
\hline 31 & $\widetilde{x}=06$ & $\widehat{X}=55$ & $\widetilde{x}=18$ & $\widetilde{x=79}$ & $\widetilde{x=17}$ \\
\hline
\end{tabular}

\footnotetext{
*Indicates percent expecting change beyond their desires.
} 
1. Limited terms of office for pastors, national interdiocesan transfer programs for clergy.

2. Options for the personal lives of priests--where to live, what to wear, etc.

3. Professional standards for performance set by priests, for priests, and enforced by priests.

4. Sabbatical leaves for priests.

5. The election of the Pope by the bishops of the world with a limited term of office.

Hierarchicals have a minority of men supporting such changes--with the single exception of professional standards set by clergy and enforced by clergy. In most cases approximately 20 to 40 per cent of the Hierarchicals support such change while approximately 80 per cent of the Egalitarians do so.

Finally, another sizeable majority--approximately 60 to 70 per cent--of the Egalitarians support:

1. Limited terms of office for bishops.

2. Priests entering professions of medicine, government, law, and the like if they feel there is a ministry they wish to pursue.

3. Small group ministry, floating parishes and the like.

4. Election of the Pope by the bishops of the world with a limited term of office. In contrast, less than 20 per cent of the Hierarchicals support such changes.

\section{Summary}

The evidence continually supports the proposition that associated with the three orientations above are more comprehensive and extensive commitments to how the religious institution should be structured, what its goals are, and what the position of the priest is as a central figure in that community. The first--those who see the church being a hierarchically dominated Christian community--fundamentally support the restructuring commitments from the bishops of the world as reflected in the documents of Vatican II. They view the central form of leadership as emanating from that source and tend to view their task as serving those commitments and orientations. The second group, while smaller, tend to extend the definitions bearing on authority, decisionmaking, and other activities in the church to include a greater participation by the clergy themselves. They tend, however, to be a transitional group both in terms of age and degree of reaction to the traditional authority structure between the Hierarchicals and Egalitarians. The third type--those we have described as having a greater commitment to an egalitarian-type decision-making structure--tend to be most radical in their perceptions of structure, authority, the occupational role of the priest, and character of the religious community. It should be underscored, nevertheless, that they place the same priorities on the general character of activities of the priesthood and priestly functionaries, but it is the character and type of activities involved which they prefer changing. Throughout, their commitment to church, faith, and priesthood is as firm for all three types. Institutional change in the church hierarchy itself, and the role of the priest, the character and scope of the mission church and priest fulfills--social and sociological changes rather than faith, liturgical, or dogmatic-are the essential characteristics of difference in the three types.

A review of the socio-demographic data related to the three types points to the fact that clergy Egalitarians are both young and, in terms of their present position, institutionally powerless. This suggests that within a clergy generation or two the changes described above will be a reality.

Yet, it is not a simple matter of setting the clock of social history ahead two nore occupational generations to predict future occupational or organizational forms. First, there is the well known phenomenon of ideological regression of individuals once they taste the sweetness of institutional power. Second, there is the rapidity of 
social change that is occurring at increasing rates, rather than linear--the tally, for example, of 11,000 clergy departures over a six year period compared to the predicted 20,700 figure over only a five year period. And this latter fact is perhaps more the rub.

The clergy most oriented to occupational and organizational change are the Egalitarians. They are also undergoing the most personal stress in their present role, i.e., high frustration from organizational constraints and the highest incidence of potential departure from the priest-professional role. There is, then, a literal race with time in the making. On the one hand there is the possibility of revolutionary change in the occupational role of the priest--if change occurs at an increasing rate. Yet, there is the other possibility that in the span of two clergy generations the inheritors will have vanished.

\section{Footnotes}

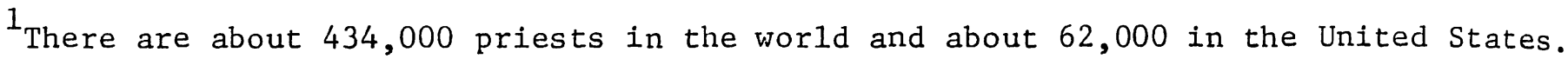
Approximately 11,000 are believed to have left the active ministry between 1963 and 1969. The source cited above projects another 20,700 departures between 1970 and 1975 .

2 A major example of this phenomenon is the National Federation of Priests' Councils. It is a "non-legitimate" organization in the eyes of the church hierarchy since it is not sanctioned by any official church body. Yet, it claims to represent approximately 32,000 catholic clergy.

${ }^{3}$ As a federation of priests' councils, the NFPC does not have individual men who affiliate. Groups of men--councils of priests--are the basis of affiliation. A vote of two-thirds of the senators of the local council results in an affiliation with the national federation.

*Revision of a paper originally read at the joint meetings of the Religious Research Association and the Association for the Sociology of Religion, Denver, Colorado, August, 1971. We are indebted to the National Foundation of Priests' Councils who supported the national study reported here.

\section{References}

Fichter, Joseph $\mathrm{H}$.

1966 Religion As An Occupation: A Study in the Sociology of Professions. Notre Dame, Indiana: University of Notre Dame Press.

Freidson, Eliot

1970 Profession of Medicine: A Study of the Sociology of Applied Knowledge. New York: Dodd, Mead and Company.

Greenwood, Ernest

1957 "Attributes of a profession." Social Work: 2: 44-55.

Hall, Oswald

1946 "The informal organization of the medical profession." Canadian Journal of Economics and Political Science 7: 30-41.

Hall, Richard H.

1969 Occupations and the Social Structure. Englewood Cliffs, New Jersey: Prentice-Hall, Inc.

Kennedy, Eugene

1968 "The dissolution of clerical culture." The Critic (August-September): 10-15. 
Moore, Wilbert E.

1970 The Professions: Roles and Rules. New York: Russell Sage Foundation.

National Catholic News Service, Washington, D.C. August 3, 1971.

Taylor, Lee

1968 Occupational Sociology. New York: Oxford University Press. 